\title{
Perspectives to Understand the Relationship between Religion and Communication
}

Jisoo Kim ${ }^{1}$ and Chulho $\mathrm{Kim}^{2}$

Division of International Studies, Korea University, 145, Anam-ro, Seongbuk-gu, Seoul, 02841 South Korea

Department of Advertising and PR, Cheongju University, 298, Daesung-ro, Cheongwon-gu, Cheongju, 28503 South Korea

\section{Abstract}

This paper emphasizes the necessity of interdisciplinary approach and suggests three basic viewpoints: absolute value-based perspective (AVBP), symbiotic value-based perspective (SVBP), virtue value-based perspective (VVBP) to understand the relationship between religion and communication in a modern society with cross-culture and diversity.

The perspective centered on absolute value, inside-out sight, is one that is based on religion's unique identity and applies it to non-religious phenomena. The main concept is the absolute proposition execution of religion's absolute values. The perspective centered on symbiotic value, outside-in sight, is one that is based on non-religious, general, common ethicality and connects it to execution of the essential purpose of religion. The macro-proposition execution of symbiotic values is emphasized.The perspective centered virtue value, human-based insight, is based on human character, the original target of insight in religion, and attempts to connect this to the execution of religion's fundamental meaning. The main concept is the anthropocentric proposition execution of virtue values.

Ultimately, when we consider modern society as an overlapping community where multiple cultures and religions coexist and globalization and localization run parallel, for religion to meaningfully affect human communication, each religion should preserve its identity, but effort from each religion to realistically apply this identity to create a general value for symbiotic coexistence is needed. Also, this paper suggests that the process of social execution should ultimately be understood and progressed within a broad viewpoint considering the good nature of humans reflected by the essence of religion.

\section{Introduction}

Religion executes a positive role by providing purpose and meaning to people's lives[1], contributing to life satisfaction in the changing modern society, and strengthening the bond and sense of belonging as a member of society[2] and easing inner conflicts[3].The fundamental significance of communication is in the sharing of meaning among related agents through reciprocal exchanging of value expectation[4]. As the basic structure of communication has a sender and a receiver, the message, regardless of the sender's intentions, can have various effects on the social environment surrounding the receiver, and this influence has continuous variability along with the change of sociocultural, environmental, periodical paradigms.

Thus, the reality that religion in modern society can function as a direct reason for social change and integration as well as a major factor that induces social restrictions and conflicts among cultures in a time when the global environment settles and expands, leading to social culture's amalgamative change in paradigm, timely reconfirms the perspective that views the relationship between communication and religion, comprehends their strengths and weaknesses and influence, and presents the necessity to find an ideal way to apply this socially. Such a perspective believes that the background of the foundation of the insight about the essence of religion, what influence religion has on human communication, the relationship between communication and religion, the necessity of smooth communication among religions and etc. in modern society should be an interdisciplinary approach and an integrated understanding about various social phenomena diversifying after multiple changes.

From a sociocultural perspective, the generalization of the global society has vitalized exchange among cultures and expanded cross-
Publication History:

Received: March 17, 2016

Accepted: June 04, 2016

Published: June 06, 2016

\section{Keywords:}

Religious Communication, Absolute Value, Symbiotic Value,Virtue Value, Multi-religion Society cultural social traits. This phenomenon inevitably continuously expands the overlapping areas where multiple religious societies based on multiple cultures coexist.Thus, communication based on different religions fundamentally requires an approach that multiple religions in human society are caused by unique cultural diversity, not basic mechanism of conflict.This is in line with the traditional perspective that a multiple religion system is richness of human culture[5], and the viewpoint that regards peace among religions as world peace[6].

However, for this approach, the possibility of different societies' cultures conflicting cannot be excluded. Furthermore, if a difference in religion causes conflicts in communication among different cultures, there is the realistic problem that deducing a rational solution is difficult because of each religion's unique absoluteness.If religion is connected with politics, conflicts about communication may result in severe regional and national problems beyond conflicts among cultures.Former research on religious hostility[7], religions' exclusive absoluteness[8], the violent disposition in the abyss of religions[9], and the double-sidedness of religions[10] directly shows the dangerousness of these problems.

From an ethical philosophical perspective, the unbalance between

*Corresponding Author: Dr. Chulho Kim, Department of Advertising and PR, Cheongju University, 298, Daesung-ro, Cheongwon-gu, Cheongju, 28503 South Korea; E-mail: philosea@cju.ac.kr

Citation: Kim J, Kim C (2016) Perspectives to Understand the Relationship between Religion and Communication. Int J Journalism Mass Comm 3: 117. doi: http://dx.doi.org/10.15344/2349-2635/2016/117

Copyright: () $2016 \mathrm{Kim}$ et al. This is an open-access article distributed under the terms of the Creative Commons Attribution License, which permits unrestricted use, distribution, and reproduction in any medium, provided the original author and source are credited. 
cognition of the truth and execution of the truth caused by a reasonoriented society makes us realize that humans are not just existences whose lives are driven by the objective results based on rational reason, but existences that also live with subjective illumination as a principal agent of life.Thus, the result of prioritizing human reason as an agent of thinking and objectifying nature is the development of civilizations and mass production of material wealth, but the series of actions to recover values based on subjective truth such as emotions and spirituality, which were relatively suppressed and distorted, is arousing new introspect and beliefs about humans' moral characters and virtue.Because humans in modern society who had the experience of malaise of capitalism confirmed the fact that subjective pursuit of truth must not be distorted excluded in humans' life for the simple reason that it may not be objectified or rationalized by reason.

Considering that spirituality, a concept that has a strong religious tone, basically presents the direction of life's meaning and purpose[11] and provides advisable values and meaning in individual lives[12], the arousal of spirituality is connected to the essence of religion that has 'returning to human nature to find the true self' as its original value. Therefore, the reconfirmation of spirituality that was hidden under the shadow of reason is related with the establishment of human value[13], and with the arousal of the existence of one's true self, it can function as a motive for empathy to evoke communication and harmony among religions sharing human-based intrinsic values as a medium.Furthermore, the rediscovery of spirituality and arousal of the existence of one's true self help ideal mental interaction in human communication actions and help improve individual values and life quality as a complete being.

From the perspective of human's social intention, the new understanding of human virtue value for communities, something overlooked by individualism, also gives a new task to modern society aiming for symbiotic values.It is because individualism prioritizes individual independence and freedom[14], considers individual profit more important than a group's profit [15] and etc. and includes a somewhat antisocial nature, which contributes to the critical weakness that social morality and awareness of shared values is realitvely weak.

Virtue value concentrates more on humans as doers than the actions and is the value that considers good character and virtue related to general human ethicality as the basis of human behavior and social relationships. Thus, a community that requires humans' virtue value transcends the narrow concept of groups as a group of a specific culture or religion and is a human community concept based on multiple cultures and religions. Religion communication or religions' effect on human communication under this perspective should focus on arousal of the intrinsic value of religion and sharing humanity's intrinsic virtue value as social beings.

From a cultural anthropological perspective, the lives of humans advanced having diversity because of regional, environmental traits and differences caused by civilizations, and, following this, religion also exists diversely and uniquely depending on the differentiated relative traits of each society.This phenomenon, to understand communication from each religion, about each religion, and between the religions, emphasizes the necessity of an approach based on anthropological relativism and religious pluralism.Attempts to read the flow of human civilization as religion[16], attempts to understand religion based on cultural customs and traditions from previous studies support this perspective.
From this perspective, religion is deeply related to cultural, regional customs and each society's traditional values, so the importance of reciprocal communication for enhancing mutual understanding among different customs and values requires continuous attention, arousal, execution and adjustment.

The perspectives mentioned above require that the importance of the connection between religion-communication should be shed new light to fit the rapidly changing modern political, economical, social, and cultural paradigms. Then, in modern global society with crossculture traits, how can religion have a meaningful effect on acts of human communication? With what point of view must the relationship between religion and communication be seen?As an alternative to the above questions, this paper suggests an exploratory perspective about the connection between religion and communication below. By applying a reconfirmation of perspectives on religion and communication and reflecting the new paradigm emphasizing the essence of religion' and man's general 'moral character, this suggests an exemplary viewpoint that helps understand the relationship between religion and communication in such changing times.

\section{Three Basic Perspectives}

\section{An absolute value-based perspective on religion and communication}

This perspective emphasizes that the approach to understand the relationship between religion and communication should follow the absolute proposition executing religion's absolute value. Thus, this viewpoint believes that the basis of communication is also from belief in religion's identity and absoluteness because it assumes that the basis of all human/social actions to pursue value us religious identity and absoluteness. Such an approach towards religion and communication considers absolute trust in religion a more important concept than universal ethical values and tries to make a specific religion's unchangeable subjective ideas the basis of communication.

Thus this perspective can be explained as inside-out sight, in which people place their attitudinal base on their religion's unique identity and apply this to non-religious phenomena. Religious communication acts using this approach are a process to get the answer to the question: What religious communication acts correspond with the realization, preservation, and strengthening of the absolute value of my religion?With this viewpoint, human actions and communication motives based on religion's absoluteness/identity are always justified. However, when based on religion's absoluteness/identity, this also may include a one-way sense of value that can justify actions considered unethical from a universal perspective and actions that destroy the symbiotic relationships in the global society. Thus, regardless of the good results this perspective may result in, it holds to the perspective that communication motives going against a religion's absolute power cannot be justified.

The positive aspect of this viewpoint is that it can function positively by unifying those of the same religion by securing absoluteness, deeply strengthen a religion's inner capability by enhancing the religion's legitimacy and identity, pursue common good by building spiritual communities with fellow believers, and notify, expand, and reinforce the religion through the vitalization of communication.

The negative aspect of this perspective is that there is a high chance for conflicts with other religions to occur because a self-centered 
analysis of a subjective viewpoint based on absoluteness is claimed to be an objective truth. Such conflicts do not end as a difference in opinion and are expressed through absolutely exclusive selfjustifications that cannot be judged by reason and can ignore, disregard, and distort common ethical values. In extreme cases, this viewpoint insists that communication should be used as a method to inform, reinforce, and expand a certain religion, and conflicts among the religions' absoluteness and identity can cause cultural conflict, isolation, and exclusion that run counter to the global society. This viewpoint makes it easy for non-religious members of society to think that all political, economical, social, and cultural conflicts are caused by a difference in religion-based communication. Also, the level of distortion an average person has about a specific religion's essential value is proportional to the intensity of such phenomena.

\section{A symbiotic value-based perspective on religion and communication}

This perspective argues that an approach to the connection between religion and communication must follow the macro-proposition executing symbiotic values. Symbiotic value is a value in which the acting agents as social beings pursue harmonic and ideal symbiosis based on mutual understanding and trust where politic, social, cultural and environmental varieties coexist.

Thus, as the execution of symbiotic values is the foundation of all human actions and social relationships, it hints that the basis of communication and the connection between religion and communication should both place the foundation at the pursuit of human symbiotic value. It prioritizes universal human ethical values and aims to find the intersection of the general moral values of religions to use as the foundation of communication for symbiosis Thus, this perspective, outside-in sight, is an attitude based on nonreligious universal, objective ethics and tries to connect such ethics to practicing religion's fundamental meaning. Religious communication acts in this approach are a process to get the answer to the question: What religious communication acts correspond with the execution, preservation, and strengthening of a symbiotic value in modern society?

From this viewpoint, the motives for actions based on religious absoluteness are not always justified. It adheres to the value that though acts may be based on religious absoluteness, actions unethical from a general point of view and actions that break symbiotic relationships in global cross-cultural societies cannot be justifiable.Thus, it means that, for good results for many people, communication actions that broadly surpass religious absoluteness can be accepted as exceptions. In other words, actions bringing good results by enhancing symbiotic value in a society can be broadly accepted.

Moreover, this perspective considers relativism about various cultures from an anthropological standpoint and requires voluntary effort to find the symbiotic intersection among the general ethicality of each religion.However, this viewpoint poses three questions: With what criteria will general ethicality of the religions be measured and counted? Who can decide if the results from the above process help society's symbiosis? Is ignoring the unique traits of religions excluded from general ethicality justifiable? and includes the problem that, in extreme cases, it can seem as if people are denying the absoluteness of religions.

\section{A virtue value-based perspective on religion and communication}

This viewpoint suggests that an approach about the connection between religion and communication should follow the anthropocentric proposition executing virtue values. Virtue value puts more importance on behavior based on good character and virtue than the right behavior.Virtue value, therefore, considers good character and virtue related to general human ethicality as the basis of human behavior and social relationships, which means the foundation of communication and the connection between religion and communication must also be good human virtue reflected in the roots of religion.

Such a perspective also has an attitude that considers both internal self-examination and external coexistence. Thus, it aims to solve differences among religions' absolute authority and identity in a win-win oriented way with love for humanity based on good human character and general ethicality. Thus this perspective, humanbased insight, is based on human virtue, the original target of insight in religion, and tries to connect it to execution of religion's fundamental meaning. Religious communication acts taking this approach are a process to get the answer to the question: What religious communication behaviors correspond with the realization, preservation, and strengthening of basic human virtue value?

Although religion is a spiritual concept that cannot be measured by rational standards, each religion's absoluteness causes a strong subjective trait. In order to pursue symbiotic values through smooth communication among religions, objectifying each religion's subjectiveness is needed. To do this, common points among the religions' subjectiveness must be found, and this is possible by reconfirming the basic virtue of humans. In short, this perspective finds it necessary to establish virtue values based on general ethics. Thus, as religious conflict is related to cultural differences as well, conflict should not be regarded as a potential problem that should be removed, but be regarded as objects that should be considered to achieve symbiosis. From this perspective, attempting to understand other religions and cultures should be done from a broader viewpoint to find, set, expand, and reinforce symbiotic values through confirmed sharing of mankind's true self, character, etc.

Table 1 organizes the three perspectives to help understand the relationship between religion and communication.

\section{Result}

Wide roads in big mountains may be well known, but hikers can lose the path if they read the signs wrong. Scholars on the path of learning must try to see interdisciplinarily to have multiple perspectives about events, so believing and agreeing with only one perspective in the process makes it easy to lose the original traits and objectives of studying. However, by returning to the interdisciplinary balance, there is nothing more to lose, no need to stray, and no reason for dispute.

The fundamental aim of most religions is one, returning to a human centered true self. If people return to a good character based ongeneral ethicality and maintain the essence, the reason for conflict in communication disappears and conflicts about what is right and what is wrong lessen. Humans are no longer agents that rely only on reason and rationality to process information and make decisions, and it is no longer an age when perspectives based on a specific culture 
Citation: Kim J, Kim C (2016) Perspectives to Understand the Relationship between Religion and Communication. Int J Journalism Mass Comm 3: 117. doi: http://dx.doi.org/10.15344/2349-2635/2016/117

Page 4 of 4

\begin{tabular}{|l|l|l|l|l|}
\hline Perspectives & Proposition & Intended Sight & Attitude & $\begin{array}{l}\text { Behavior of } \\
\text { Pursuing Religious Communication }\end{array}$ \\
\hline $\begin{array}{l}\text { Absolute } \\
\text { Value-Based } \\
\text { Perspective } \\
\text { AVBP) }\end{array}$ & $\begin{array}{l}\text { Absolute proposition } \\
\text { executing religion's } \\
\text { absolute value }\end{array}$ & $\begin{array}{l}\text { Inside-Out } \\
\text { Sight }\end{array}$ & $\begin{array}{l}\text { Attitude placing humans' } \\
\text { attitudinal base on their } \\
\text { religion's unique identity and } \\
\text { applying this to non-religious } \\
\text { phenomena. }\end{array}$ & $\begin{array}{l}\text { The process of getting the answer from the } \\
\text { question 'What religious communication acts } \\
\text { correspond with the realization, preservation, } \\
\text { and strengthening of the absolute value of my } \\
\text { religion?' }\end{array}$ \\
\hline $\begin{array}{l}\text { Symbiotic } \\
\text { Value-Based } \\
\text { Perspective } \\
\text { (SVBP) }\end{array}$ & $\begin{array}{l}\text { Macro-proposition } \\
\text { executing symbiotic } \\
\text { value }\end{array}$ & $\begin{array}{l}\text { Outside-In } \\
\text { Sight }\end{array}$ & $\begin{array}{l}\text { Attitude based on non- } \\
\text { religiousuniversal, objective } \\
\text { ethics and trying to connect } \\
\text { such ethics to practicing } \\
\text { religion's fundamental }\end{array}$ & $\begin{array}{l}\text { The process of getting the answer from the } \\
\text { question 'What religious communication acts } \\
\text { correspond with the execution, preservation, } \\
\text { and strengthening of a symbiotic value in } \\
\text { modern society?' }\end{array}$ \\
\hline $\begin{array}{l}\text { Virtue } \\
\text { Value-Based } \\
\text { Perspective } \\
\text { (VVBP) }\end{array}$ & $\begin{array}{l}\text { Anthropocentric } \\
\text { proposition } \\
\text { executing } \\
\text { virtue value }\end{array}$ & $\begin{array}{l}\text { Human-based } \\
\text { Insight }\end{array}$ & $\begin{array}{l}\text { Attitude based on human } \\
\text { virtue, the original target of } \\
\text { insight in religion, and trying } \\
\text { to connect itto the execution } \\
\text { of religion's fundamental } \\
\text { meaning. }\end{array}$ & $\begin{array}{l}\text { The process of getting the answer from the } \\
\text { question 'What religious communication } \\
\text { behaviors correspond with the realization, } \\
\text { preservation, and strengthening of basic human } \\
\text { virtue value? }\end{array}$ \\
\hline
\end{tabular}

Table 1: Three perspectives helping understanding the relationship between religion and communication.

are given enlightening legitimacy. This is because humans must live together in a global society where multiple cultures coexist politically, economically and socioculturally.

This paper presents three perspectives: an absolute value-based perspective, a symbiotic value-based perspective, and a character value-based perspective to understand the relationship between religion and communication. However, the purpose of this is not to prove that a certain viewpoint about the relationship between religion and human society is right or wrong, better or worse. It is just to reconfirm the essence of religion for human life according to the flow of time and find a way of harmony and coexistence through ideal communication in modern society based on multiple cultures religions.

\section{Conclusion}

In conclusion, judgment of actions based on religious absoluteness varies for every religion, but what most people expect through religion is similar. Thus, for religion to meaningfully affect human communication, the identity of religion should be kept, but effort to realistically apply that identity to create a common value for symbiosis in a rapidly changing global society is needed. This is because the essence of religion finds meaning in its existence when it is expressed as a social action based on general ethicality.

\section{References}

1. George LK, Larson DB, Koenig HC, McCullough ME (2000) Spirituality and health: What we know, what we need th know. Journal of Social and Clinical Psychology 19: 102-116.

2. Mahoney AK, Pargament KI, Swank AM, Swank NM (2003) Religion and the Sanctification of Family Relationships. Review of Religious Research 44: $220-236$

3. Mattis $J(2002)$ Religion and spirituality in the meaning making and copingexperience of African American women: A qualitative analysis. Psychology of Women Quarterly 26:308-320.

4. Kim C (2014) An Exploratory Study on Measuring Users' Value Expectation at Bus Shelters: Focused on Seoul Area. Journal of Brand Design Association of Korea 30: 143-158
5. Smith WC (1976) Religious Diversity, Crossroad, New York.

6. Kung $\mathrm{H}$ (1987) Christianity and World Religions: Dialogue with Islam as one Model. The Muslim World 77: 80-95.

7. Coward H (1986) Intolerance in the World's Religions. Studies in Religion15: 419-431.

8. Seul JR (1999) Ours is the Way of God': Religion, Identity, andIntergroup Conflict. Journal of Peace Research 36: 553-569.

9. Juergensmeyer M (2001) Terror in the Mind of God: The Global Rise of Religious Violence, Berkeley L. A.: University of California Press. 6.

10. Nepstad SE (2004) Religion, Violence, and Peacemaking. Journal for the Scientific Study of Religion 43: 297-301.

11. Mille WR,Thoresen CE (2003) Spirituality, Religion and Health: An Emerging Field of Research. American Psychologist 58: 24-35.

12. Neff JA (2006) Exploring the dimensionality of religiosity and spiritualityin the Fetzer multidimensional measure. Journal for the Scientific Study 45: 449-459.

13. Seaward BL (1991) Spiritual Wellbeing: A Health Education Model. Journal of HealthEducation.22(3): 166-169.

14. Triandis HC (1990) Cross-cultural studies of individualism-collectivism. Nebr Symp Motiv 37: 41-133.

15. Wagner JA (1995) Studies of individualism-collectivism: Effects on cooperation in groups. Academy of Management Journal 38: 152-172.

16. Huntington SP (1996) The Clash of Civilizations and the Remaking of World Order. New York. Simon \& Schuster Paper backs. 